\title{
Abortion across (some) borders?
}

Sethna, C., \& Davis, G. (Eds.). (2019). Abortion across borders: Transnational travel and access to abortion services. Baltimore, Maryland: Johns Hopkins University Press.

\$59.95 ISBN: 9781421427294

Abortion access is a highly contested issue that is playing an increasingly vocalised role in politics and the media. From the systematic Republican attacks on access in the United States and the continued campaigning to highlight the unequal abortion law in Northern Ireland, abortion access in the Global North has been making headlines. Abortion Across Borders, an edited collection by Christabelle Sethna and Gayle Davis, tasks itself with focusing a scholarly lens on abortion access. The book responds well to the timeliness of this issue with the final chapter, by Niklas Barke, explaining the likely impact on abortion access in Britain under different Brexit scenarios. Through an introduction by the editors and twelve empirical chapters, a rich picture of abortion access is advanced in this beautifully presented volume.

The book is divided into three sections: Flight risks, Domestic transgressions, and Democratic transitions. Flight risks comprises three chapters that examine international travel for abortions in the 1960s and 1970s. Domestic transgressions encompasses five chapters that focus on abortion travel within national boundaries, and the final section, democratic transitions, covers four chapters on abortion access under various changes of governments in Europe. According to the editors, "[t]his is the first edited volume to provide a strong focus specifically on the transnational aspects of travel, in the broadest sense of the word, for abortion services in the past and present" (p.1). This book does meet this aim but with one troubling omission, it ignores the Global South. 
The geographical focus of this edited collection is the Global North: North America, Europe, and Australasia. The editors do nod to this in the introduction saying, "[i]t is but a small snapshot of transnational abortion travel because there are substantial swathes of the world it does not include, namely Africa, the Middle East, Asia and Latin America" (p.2). They recognise that "[c]lose attention needs to be paid to the role of cross-border travel for abortion services in these regions" (p.3) but this doesn't do enough to justify the lack of such scholarship in this volume. It must be noted that there is unfortunately a dearth of scholarship on abortion travel in the Global South (see Pheterson \& Azize, 2005 and Freeman, 2017 for exceptions) but with twelve empirical chapters, an exclusive focus on the Global North feels wholly imbalanced. When, according to the Guttmacher Institute (2019), 49\% of abortions in the Global South are unsafe, 6.9 million women are treated annually in developing regions for complications arising from such abortions, and restrictive abortion laws are more likely to be found in the Global South, books such as these need to make a more concerted effort to go beyond the Global North.

Fiona Bloomer, Clare Pierson and Sylvia Estrada Claudio's Reimagining Global Abortion Politics, which was also published in 2019 , offers a useful comparison on this issue. While abortion travel is not the sole focus of their book, they do incorporate the issue well. It notably features in-depth case studies on organisations and countries including ones in the Global South such as the Philippines, Brazil, and Uruguay. It is this clearer commitment to abortion access in the Global South that Sethna and Davis' edited book lacks.

With the authors of Abortion Across Borders coming from a range of disciplines such as the history of medicine, women's/gender studies, architecture, sociology, geography, English, nursing, psychology and law, this truly is a multidisciplinary collection. The editors' 
ability to keep a precise and clear focus with this multidisciplinarity should be commended. They have also woven together the chapters so that each one cross-references other chapters in the volume. This is generally excellent and I have never seen this used so frequently in an edited book. However, at times it is overly gestural, a pointing toward other chapters rather than a substantial engagement with them. One area this was very noticeable in was the use of terminology around abortion travel. Many chapters have their own discussion of whether to use 'abortion tourism' (p.279), 'medical travel' (p.5), 'abortion refugee' (p.201), or 'reproductive mobility' (p.123) and this created some irregularities. A more detailed discussion of these terms and a clearer rationale of why authors chose certain terms would have aided the consistency of the book. To frame the final part of this review, I will examine the three words from the book's title: 'Abortion', 'Across', and 'Borders'.

\section{Abortion}

This volume deals very well with abortion at a multi-scalar level including national regulation, discourse around abortion in mainstream and alternative media, as well as personal experiences. Chambers, Macquarrie and Macdonald's chapter (chapter 8) on abortion access on Prince Edward Island in Canada, for example, sensitively deals with harrowing testimonies of women forced to travel or find themselves unable to travel and so self-induce abortions. There was also some interesting discussion on the non-legislative barriers that complicate abortion access, particularly in Davis et al.'s chapter (chapter 4) on abortion provision in Britain. This aspect of the book's title, then, was excellently dealt with.

\section{Across}


The 'across' of the title received patchier attention. The editors claim in the introduction that "[p]articularly useful to this volume is strong academic interest in the "mobility turn"” (p.4) and mention that "...for a woman to access abortion services, she might travel to an abortion provider by car, train, ferry, bus, or plane" (p.4). While these modes of transport all appear in the index, theoretical work on mobility and details about these journeys were remarkably absent and more of a focus on how women actually travel for abortions would have made for a novel and fascinating contribution. A clear exception to this was Gilmartin and Kennedy's (chapter 5) excellent focus on 'reproductive mobility' to better engage with the mobility and fixity of abortion access. This is situated in the historical context of the enforced mobility of women in Ireland to mother and baby homes and asylums. Moreover, the editors do make the important and relevant point that mobility is shifting as it is abortion medication, not people, that is increasingly what crosses borders. It was a shame not to see this dealt with more thoroughly in the book.

\section{Borders}

Similarly, I was expecting much more engagement with 'borders'. This is particularly because the editors claim that "...travel for abortion services, like medical tourism itself, is best examined using a transnational lens" (p.11). This transnational lens becomes lost at points throughout the book. One of the three sections that the book is divided into, 'Domestic transgressions' (chapters 4-8), comprises chapters that look at intranational abortion travel. According to Sethna and Davis, "[t]his part provides ample evidence of abortion travel as contained within national boundaries, giving pause to those how assume that medical tourism occurs only across international borders" (p.14). How, then, are borders being thought of here? Regional? Jurisdictional? Cultural? A clearer explanation of this term and the 
different ways it is being used would have given the book a more convincing steer on what it adds to understandings of borders.

Overall, this is a timely and important book that deserves a readership as diverse as its authors. There is undoubtedly much to gain here for students and scholars interested in abortion access from any disciplinary perspective. While I have highlighted some issues with the framing of the volume and the exclusion of the Global South, the empirical chapters provide a much-needed and thorough examination of historical and contemporary obstacles to abortion access and the mobilities that have emerged to resist them. My hope is that this book lays the foundation for equally rich studies of abortion access beyond just North America, Europe, and Australasia.

\section{References}

Bloomer, F., Pierson, C. \& Estrada Claudio, S. (2019). Reimagining global abortion politics: A social justice perspective. Bristol: Policy Press.

Freeman, C. (2017). The crime of choice: Abortion border crossings from Chile to Peru. Gender, Place \& Culture, 24(6), 851-868.

Pheterson, G., \& Azize, Y. (2005). Abortion practice in the northeast Caribbean: "Just write down stomach pain". Reproductive Health Matters, 13(26), 44-53.

Guttmacher Institute (2019). International abortion. Retrieved from https://www.guttmacher.org/international/abortion 
Dr Cordelia Freeman, PhD, University of Nottingham. School of Geography, Sir Clive Granger Building, University Park Campus, University of Nottingham, NG7 2RD, UK. 01158468507 